\title{
Design and Analysis of Pyro Based Transportation Lock and Release Mechanism for Smaller Flight Vehicle
}

\author{
R.Santhanam $\dot{\AA}^{*}$, CH Surya Kiran ${ }^{\dot{\mathrm{B}}}, \mathrm{P}^{\mathrm{C}} \mathrm{Jain}^{\dot{\mathrm{A}}}$ and PSR Anjaneyulu ${ }^{\dot{\mathrm{A}}}$ \\ À Defence R \& D Laboratory, Hyderabad \\ ${ }^{\dot{B}}$ Advanced Systems Laboratory, Hyderabad
}

Accepted 10 January 2014, Available online 01 February 2014, Special Issue-2, (February 2014)

\begin{abstract}
Pyro based mechanisms are generally used in flight vehicles for various purposes. Here, a pyro based transportation lock and release mechanism has been designed to lock (arrest the movement of) the flight vehicle to the container tube during transportation and handling (in the captive mode) and to release the flight vehicle before the firing. In this paper, Classical Design and Finite Element Analysis of the individual components (piston, pyro body, flange and shear pin) and the assembly of the transportation lock and release mechanism are presented. This mechanism has been fabricated, ground tested and field tested successfully in flight trials.
\end{abstract}

Keywords: pyro based mechanism, lock and release mechanism, Classical Design and Finite Element Analysis

\section{Introduction}

Various mechanisms based on pyro techniques are generally used in flight vehicles for separation of stage and lock and release of the vehicle etc., For a mission to be successful, all these mechanisms should perform their intended functions at the desired times. A smaller flight vehicle will be kept in container during transportation and handling. In order to avoid the movement of the flight vehicle during transportation and handling, a locking arrangement is required. A pyro based transportation lock and release mechanism has been designed to lock (arrest the movement of) the flight vehicle to the container tube during transportation and handling (in the captive mode) and to release the flight vehicle before the firing. This is very critical mechanism as far as the launch of the flight vehicle is concerned. Because malfunctioning of this mechanism leads to affect the launch of the flight vehicle. So care must be taken while designing this system. Initially, the basic dimensions of the individual components are derived from the classical design approach. The modeling of the components as per the derived basic dimensions has been done using SOLID WORKS and they have been taken to ANSYS environment for carrying out Finite Element Analysis.

A pin puller design, which was used for the successful deployment of an antenna on the surface of Mars in 1976 in the Viking Lander Program, failed to function in a second application in 1986 and was abandoned. A spacecraft separation joint failed to function in a 1984 ground test after more than 20 years of flight successes;

*Corresponding author: R.Santhanam the same joint, which is designed for full containment of explosive products, burst in 1994 during release of a payload from the Space Shuttle cargo bay. A "fully qualified" valve design that was created for the Gemini Program in the early 1960's, structurally failed and ignited hydrazine in 1994 through previously unrecognized failure modes. Improved guidelines for pyrotechnic design, development and qualification are clearly needed. An article published by Laurence J. Bement in NASA Technical Memorandum 110172 manual provides an overview of and recommendations for the design, development, qualification, integration and use of pyrotechnic components and the systems in which they are used. The objective of this manual is to remove the art from pyrotechnic applications and introduces engineering approaches. First and foremost thing of any of this system is its proper design and analysis before the development and qualification. The paper published by $\mathrm{M} \mathrm{K}$ Abdul Majeed et al on the separation and staging mechanisms for Indian SLV-3 Launch Vehicle describes a unique separation and jettison system for the ascent fairing and a staging system for the apogee motor. The paper published by Ganesh and Wadkar describes the detailed analysis of ball lock release mechanism to assess the contact stresses between balls and rings in the most heavily loaded zone, which gives the contact deformation and stress contours. The paper published by $S$ Somanath et alpresents a dynamic model developed for simulation of three different types of designs of pyro actuated ball lock separation system for micro satellites. The model was used to evaluate the impact forces that generate shocks and the results are verified experimentally. Most of the literatures describes about the design, development and qualification 
of the pyro charges i.e., explosives part. There is lack of data available regarding the design and analysis of mechanical part of the pyro system for which the references are used.

Here, the mechanism proposed is simple, less number of parts, easy to fabricate, lesser weight, more force to weight ratio and more force will be generated within less time and smaller volume of space. To the best of the author's knowledge, no paper is describing about the detailed and step by step procedure adopted to design this kind of lock and release mechanism assembly. This mechanism has been fabricated, ground tested and field tested successfully in flight trials.

\section{System description and working principle}

Configuration details of Transportation Lock and Release Mechanism (TLRM) is shown in the Figure-1 (a) and the Figure 1 (b) shows the solid model of the same. Transportation Lock and Release Mechanism mainly consists of three components namely piston, pyro body, and flange, driven by pyro cartridge and shear pin
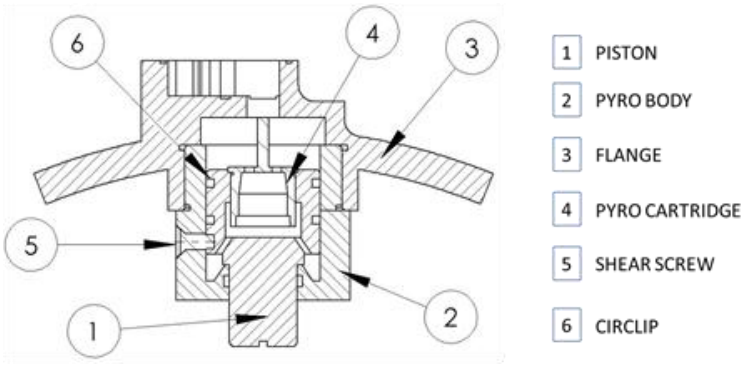

Figure-1(a) Configuration of TLRM

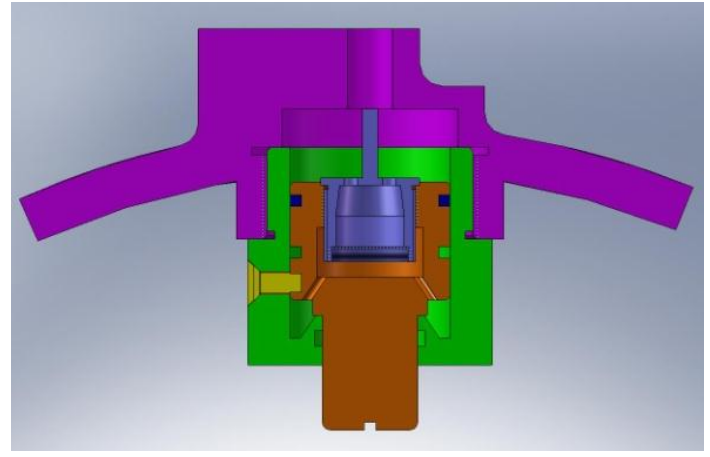

Figure-1(b) Solid Model of TLRM

Piston serves as a locking pin and also houses pyro cartridge. Pyro body houses the piston and pyro cartridge together. The mechanism is mounted on the Container Tube by means of a flange. Piston holds the pyro cartridge at its head and the other end of the piston (piston pin) will engage in to the cavity of the built up area in the flight vehicle section. The piston and the pyro-body are locked in position by means of a shear pin. High-pressure gas sealing is provided by means of ' $\mathrm{O}$ ' ring and gasket. When pyro is ignited high pressure gas will be generated inside the piston cavity at its head. This gas will pass through the
4 holes in the piston and enter into the space between the body and the piston and pushes the piston upwards which breaks the shear pin. When the piston is moved up by certain distance in $\mathrm{mm}$, the flight vehicle is unlocked from the container tube and ready for launch. As the piston moves up and reaches the step the circlip expands and locks the piston at that position so that it will not come down. There is a sensor unit (which is not shown in the figures) provided at the top of the flange to detect whether the piston is released completely or not. Once this sensor unit senses that the piston is completely released then the flight vehicle will be fired.

Transportation Lock and Release Mechanism under various operating conditions are shown in the following figures 2 (a), 2 (b) and 2 (c). Figure 2 (a) shows the piston in fully engaged condition (i.e., completely locked). Figure 2 (b) shows that the piston is partially released (i.e., around $50 \%$ released - in the process of releasing). Figure 2 (c) shows the piston in fully released condition (i.e. completely released before firing).

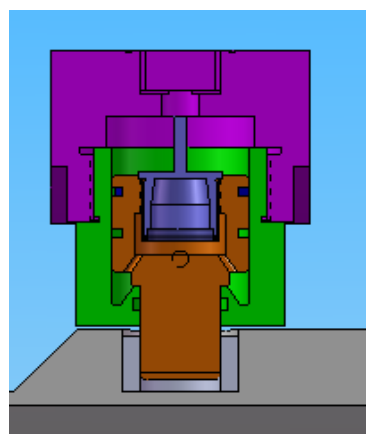

Figure-2 (a) fully engaged

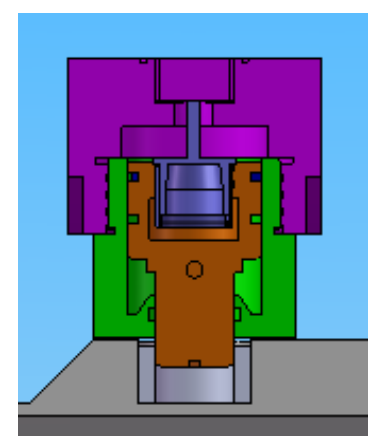

(b) partially released

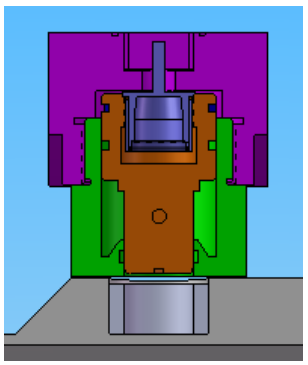

Figure-2 (c) Fully released

\section{Design and analysis}

\section{Load}

Total load $(\mathrm{F})$ on the piston of TLRM = Mass of the vehicle (m) $x$ Acceleration of the vehicle (a) during transportation / handling in an integrated condition (flight vehicle locked with container tube).

\section{Material and its properties}

Material selected for fabrication for piston, body and flange is 13-8 PH steel because it has higher strength, ductility and toughness properties which are required for withstanding the shock loads. 
Mechanical Properties:

The mechanical properties of this material at room temperature are given below.

Young's modulus $\mathrm{E}=2 \mathrm{e} 5 \mathrm{MPa}$

Ultimate tensile strength

UTS = $1413 \mathrm{MPa}$

Yield strength

$\mathrm{YS}=1310 \mathrm{MPa}$

\section{Classical design}

Classical design has been carried out to find out the basic dimensions of the individual components (piston, pyro body and flange) of the TLRM considering the above loads. Vertical dimensions of the piston, pyro body and flange are fixed / determined based on the space availability. Horizontal / Lateral Dimensions of the piston, pyro body and flange are calculated based on the loads acting on the individual components of the TLRM. The detailed classical design calculations which have been carried out using strength of material approach for all the components in step by step manner are given below where $\mathrm{d}$ is a diameter of the component and $\mathrm{h}$ is the height at which the diameter of the section is taken.

Following formulae are used for arriving the basic dimensions of the individual components of TLRM.

Bending Moment $\mathrm{M}=\mathrm{F}$ x h

Allowable stress $\sigma_{\text {allow }}=\underline{\mathrm{UTS}}$ FOS

where FOS is Factor of Safety considered as 2,

$\sigma_{\text {allow }}=\frac{\mathrm{M}}{\mathrm{Z}}$

where $\mathrm{Z}$ is a section modulus

if it is solid section then diameter,

$\mathrm{d}$ is found from $\mathrm{Z}={\underline{\pi \mathrm{d}_{1}}}^{3}$

if it is hollow section then diameter,

$\mathrm{d}$ is found from $\mathrm{Z}=\frac{\pi\left(\mathrm{d}^{4}{ }_{\text {out }}-\mathrm{d}^{4}{ }_{\text {in }}\right)}{32 * \mathrm{~d}_{\text {out }}}$

In equation 5 , any one diameter either outer diameter $d_{\text {out }}$ or inner diameter $\mathrm{d}_{\text {in }}$ will be fixed and the other will be calculated.

\section{PISTON}

The representative figure of piston is shown in figure 3 .

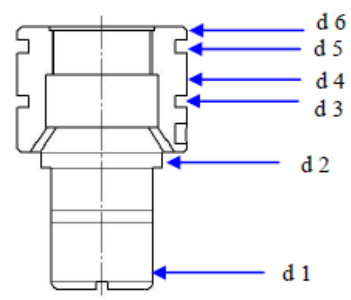

Figure-3 Piston

\section{STEP - I}

Diameter of the piston pin $d_{1}$ (Since it is a plain section) is finalized using the equations $1,2,3$ and 4 .

\section{STEP - II}

Diameter of the piston pin $\mathrm{d}_{2}$ (Since it is a plain section) is finalized using the equations 1,2,3 and 4 . Because to reduce stress concentration near the piston pin and head joint and to place the piston properly on the steps of the pyro body in the assembled condition, $d_{2}$ is higher than $d_{1}$.

\section{STEP - III}

Diameter $d_{3}$ in is fixed for keeping pyro cartridges and the diameter $d_{3 \text { out }}$ is found from the equations $1,2,3$ and 5 .

\section{STEP - IV}

Since the inner diameter at this step zone is $d_{3}$ out, and undercut of dimension $\mathrm{u}_{1} \mathrm{xu}_{1}$ is required for accommodating the gasket. So the piston outer diameter is finalized as $\mathrm{d}_{4}=\mathrm{d}_{3}$ out $+\mathrm{u}_{1}$ (one side $)+\mathrm{u}_{1}$ (other side).

\section{STEP - V}

Since the diameter $\mathrm{d}_{3}$ out (which is critical among the grooves) is finalized, this diameter $\mathrm{d}_{5}$ also finalized as $\mathrm{d}_{3}$ out (which is not that much critical comparatively). Also there is a requirement of having a groove of $\mathrm{u}_{1} \mathrm{xu}_{1}$ to accommodate the circlip at this groove. Inner diameter of the undercut zone is finalized as $\mathrm{d}_{5} \cdot \mathrm{d}_{3}$ out $=\mathrm{d}_{5}$. Diameter $\mathrm{d}_{6}$ $=\mathrm{d}_{4}$ (outer diameter of piston as a whole should be same for proper movement inside the pyro body).

\section{PYRO-BODY}

The representative figure of pyro-body is shown in figure 4

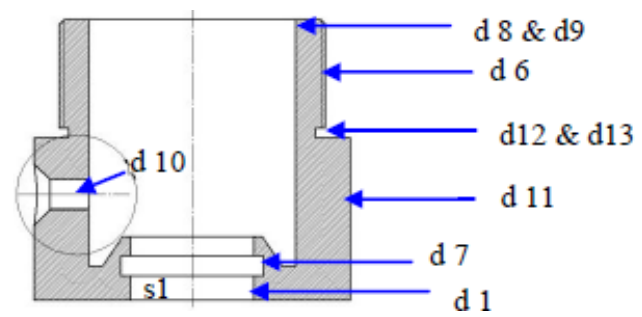

Figure-4 Pyro-body

\section{STEP - VI}

Since the diameter of the piston head is finalized as $d_{4}=d_{6}$, internal diameter of the pyro-body is also $d_{4}$ or $\left(d_{6}\right)$. Since the diameter of the piston pin is finalized as $d_{1}$, diameter of the bottom hole is also $d_{1}$. One more circular groove of diameter $d_{7}$ which is $=d_{1}+$ allowance on either end is also provided to accommodate the circular ring / the gasket. Height of the pyro-body is finalized as h4 due to the 
requirements of some clearances between piston and pyrocartridge assembly and flange.

\section{STEP - VII}

Diameter $\mathrm{d}_{8 \mathrm{out}}$ is found from the equations $1,2,3$ and 5 . Inner diameter $d_{8 \text { in }}$ is nothing but $d_{6}$. Outer diameter of the pyro-body at the top edge can be finalized as $\mathrm{d}_{8}$.

But the top edge of the pyro-body will be screwed in to the flange. The stress at the threaded region should be as low as possible. For that the diameter has to be increased. So it has been increased to next highest size of the standard thread available with some allowance.

Outer diameter of the pyro-body at the top edge is finalized as $d_{9}=M\left(d_{8}+\right.$ allowance $)$ with pitch $p_{1}$.

\section{STEP - VIII}

Equivalent pressure $\mathrm{pr}_{1}$ on step $\mathrm{s}_{1}$ is evaluated from couples $\left(\mathrm{C}_{1}\right.$ and $\left.\mathrm{C}_{2}\right)$, direct force $(\mathrm{F})$ and applied $\mathrm{pr}_{1}$ on step $\mathrm{s}_{1}$ for half circle zone. Based on the stress value, the step size $\mathrm{s}_{1}$ is finalized.

\section{STEP - IX}

Since the stepped zone is critical, a minimum thickness has to be maintained in that zone. For that the diameters of the steps have been increased to the required level (zone marked by red ellipse). Also the shear pin of diameter $d_{10}$ has to be provided in the body to keep the piston in locked condition (zone marked by blue circle) and it should So the outside diameter of the pyro-body at the bottom is finalized as $\mathrm{d}_{11} \cdot \mathrm{d}_{11}=\mathrm{d}_{4}+\mathrm{e}_{1}$ of $\mathrm{d}_{10}+\mathrm{t}_{1}$.

\section{STEP - X}

Diameter $\mathrm{d}_{12 \text { out }}$ is found from the equations $1,2,3$ and 5 whereas the inner diameter $d_{12 \text { in }}$ is same as $d_{6}$. Outer diameter of at the step of the can be finalized as $d_{12 \text { out }}$.

Since the outside diameter of the pyro-body at the top and bottom is finalized as $\mathrm{d}_{9}$ and $\mathrm{d}_{11}$ respectively, the diameter at the zone marked by red circle is finalized as $\mathrm{d}_{13}=\mathrm{d}_{9}-\left(\mathrm{u}_{2} \times 2\right.$ 2sides$)$ (because it is an undercut of $\mathrm{u}_{2} \times \mathrm{u}_{2}$ with respect to the outside diameter of $d_{9}$ at the top of the pyro-body).

FLANGE: The representative figures of flange is shown in figure 5

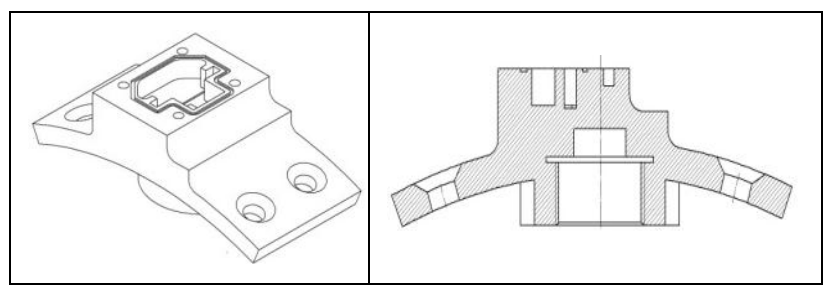

Figure-5 Flange

STEP - XI
Since the outer diameter of the pyro-body is fixed as $d_{9}$, the inner diameter of the flange also is fixed as $\mathrm{d}_{9}$. Inner curvature of the flange is having the radius of $R_{\text {in }}$ which is equal to the outer radius of the container tube to fit with metal strip / metal segment embedded in to the container tube. Outer curvature of the flange is having the radius of $R_{\text {out }}$ i.e., $\left(R_{\text {in }}+t_{2}\right)$ where $t_{2}$ is flange thickness which is a minimum requirement to with stand the loads which is coming on the flange (seen from the analysis). Since the container tube and flight vehicle assembly will be kept in a rectangular container, the total height of the flange is limited to $h_{7}$ due to the space constraint. Over the curvature of the flange there is a cavity provided to keep some standard electronics items to control the mechanism. For this, one step is provided over the curvature in which cavity is made of $h_{8}$ height. Screws of $d_{14}$ diameter have been suggested in the flange to fit the whole assembly with the container tube. Screw / Bolt which is more than 5 $\mathrm{mm}$ diameter cannot be accommodated with the metal strip embedded in to the container tube because of its thickness. Two holes of the same sizes on either side are sufficient to with stand the loads (seen from the analysis). One cavity of diameter $d_{15}$ is provided in the flange to give space for the movement of the piston and cartridge assembly when the piston is getting retracted. During the retraction of the piston the circlip will expand and place on this cavity step and lock the piston so that the piston will not come back after it is retracted from the flight vehicle i.e., after unlocking the flight vehicle from the container tube. Fastening scheme of the flange with container tube is finalized as follows using the equations $6,7,8,9,10$ and 11.
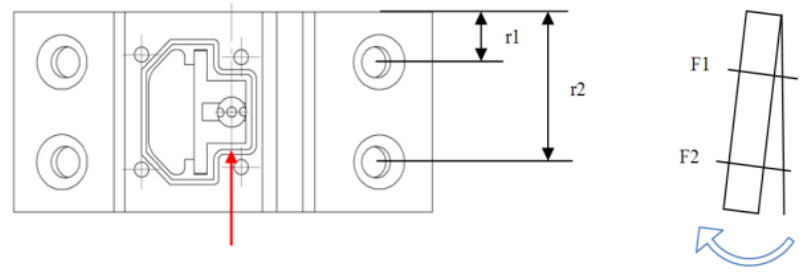

Figure-6 Flange top and side views

$$
\begin{aligned}
& \mathrm{M}=\mathrm{F}_{\mathrm{ul}} \mathrm{r}_{1} \mathrm{r}_{1}+\mathrm{F}_{\mathrm{ul}} \mathrm{r}_{2} \mathrm{r}_{2}=\mathrm{F}_{\mathrm{ul}}\left(\mathrm{r}_{1}{ }_{1}+\mathrm{r}_{2}{ }_{2}\right) \\
& \mathrm{T}=\mathrm{CdF}_{\mathrm{i}}=0.2 \mathrm{~F}_{\mathrm{i}} \mathrm{d} \\
& \mathrm{F}_{\mathrm{Tb}}=\mathrm{F}_{\mathrm{i}}+\mathrm{kF}_{\mathrm{s}} \\
& \mathrm{F}_{\mathrm{Tb}}=\frac{\sigma_{\mathrm{tb}}}{\text { Area }} \\
& \mathrm{k}=\left[\frac{\mathrm{k}_{\mathrm{b}}}{\mathrm{k}_{\mathrm{b}}+\mathrm{k}_{\mathrm{c}}}\right] \\
& \text { Principal stress } \\
& \sigma_{\text {max }, \text { min }}=\frac{\sigma_{\mathrm{x}}+\sigma_{\mathrm{y}}}{2} \pm \frac{\sqrt{\left(\sigma_{\mathrm{x}}-\sigma_{\mathrm{y}}\right.}}{2}+\tau_{\mathrm{xy}}{ }^{2} \\
& 2
\end{aligned}
$$

\section{SHEAR PIN}

The representative figure of shear pin is shown in figure 7. 


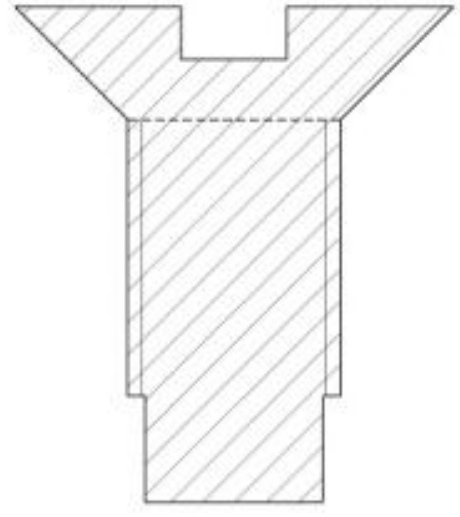

Figure-7 Shear Pin

\section{STEP - XII}

The shear pin is designed using the equations 12,1314 , $15,16,17,18$ and 19 in such a way that it has to be broken when the minimum force generated is due to the gas pressure acting under the head of the piston.

$$
\begin{aligned}
& \text { Area under the piston } \mathrm{A}_{\mathrm{UP}}=\pi\left(\mathrm{d}^{2}{ }_{\text {out }}-\mathrm{d}^{2}{ }_{\text {in }}\right) \\
& \text { Max. Force } \mathrm{F}_{\mathrm{MAX}}=\operatorname{Pr}_{\mathrm{MAX}} \times \text { Area } \mathrm{A} \\
& \text { Min. Force } \mathrm{F}_{\mathrm{MIN}}=\operatorname{Pr}_{\mathrm{MIN}} \times \text { Area } \mathrm{A} \\
& \text { Actual Force } \mathrm{F}_{\mathrm{ACT}}=\operatorname{Pr}_{\mathrm{ACT}} \times \text { Area } \mathrm{A} \\
& \text { Shear Area of the pin } \mathrm{A}_{\mathrm{SP}}=\frac{\pi\left(\mathrm{d}^{2}\right)}{4} \\
& \tau_{\mathrm{MAX}}=\frac{\mathrm{F}_{\mathrm{max}}}{\mathrm{A}_{\mathrm{SP}}} \\
& \tau_{\mathrm{MIN}}=\frac{\mathrm{F}_{\min }}{\mathrm{A}_{\mathrm{SP}}} \\
& \tau_{\mathrm{ACT}}=\frac{\mathrm{F}_{\mathrm{act}}}{\mathrm{A}_{\mathrm{SP}}}
\end{aligned}
$$

After considering all the above points (some are from the design point of view and some are from the space constraint point of view), the dimensions of the flange have been finalized.

\section{F E analysis}

Although the components are designed by strength of material approach to arrive at the basic dimensions, but to capture the precious stress distribution and to identify the stress concentration zone it is essential to carryout Finite Element Analysis (FEA) of individual components and assembly with finer details incorporated in models.

Finite Element Analysis has been carried out for the individual components and the assembly of the pyro lock mechanism using ANSYS package.

\section{Model Details}

Solid models of pyro piston, pyro body, flange and their assembly are created in SOLID WORKS modeling package according to the required dimensions and exported to FEA software ANSYS through PARASOLID translator for carrying out the Finite Element Analysis.

\section{Elements Used}

Solid models of pyro piston, pyro body, flange and their assembly are meshed with solid 92 elements. It is a 10 nodded tetrahedron element with 3 degrees of freedom (translations along each axis) at each node and well suited for curved geometries. Finite Element Models are shown in the following Figures 8, 10, 12, 14 and 16.

\section{F E Results}

F E Model plots with loads and constraints and von-mises stress plots of the individual components and assembly are given below from figures 8-17.

Figure 8 shows the FE model of piston which is constrained at its top surface and corresponding force is applied on the bottom portion of the piston pin according to the engagement length of the cavity of the built up area in the flight vehicle section. Figure 9 shows von-mises stress plot of piston in which the maximum stress observed is around $705 \mathrm{MPa}$ after neglecting the localized stresses which occurs near the stepped zones. Figure 10 shows the FE model of pyro body which is constrained at its top surface and the corresponding force is applied on the inner surface of the bottom hole of the pyro body according to the engagement length of the piston. Figure 11 shows vonmises stress plot of pyro body in which the maximum stress observed is around $670 \mathrm{MPa}$ after neglecting the localized stresses which occurs near the stepped zones. Figure 12 shows the FE model of flange which is constrained at four fastener holes and corresponding force is applied on the inner surface of the bottom portion of the flange according to the engagement length of pyro body. Figure 13 shows von-mises stress plot of flange in which the maximum stress observed is around $705 \mathrm{MPa}$ after neglecting the localized stresses which occurs near the stepped zones. Figure 14 shows the FE model of shear pin where the shear pin is constrained at its top surface and corresponding force is applied on the bottom portion of the shear pin according to the engagement length of the piston. Figure 15 shows von-mises stress plot of shear pin in which the maximum stress observed is around 171 MPa. Figure 16 shows the FE model of TLRM assembly which is constrained at four fastener holes and corresponding force is applied on the bottom portion of the piston according to the engagement length of the cavity of the built up area in the flight vehicle section. Figure 17 shows von-mises stress plot of TLRM assembly in which the maximum stress observed is around $640 \mathrm{MPa}$ after neglecting the localized stresses which occurs on the piston and on the flange near the stepped zones.

When the individual components are analysed, the more severe conditions are simulated. For example, the piston is constrained at the top when it is analysed individually but in assembly it is supported on the surrounding areas also. The idea behind this is, if the component works in more severe condition it can work in 
less severe condition safely. The results form FEA are tabulated below in Table-I:

Table-I FEA Results

\begin{tabular}{|l|l|l|}
\hline Components & $\begin{array}{l}\text { Max. von-mises } \\
\text { stress } \\
\text { from FEA }(\mathrm{MPa})\end{array}$ & F O S on UTS \\
\hline Piston & 705 & 2.00 \\
\hline Pyro Body & 670 & 2.11 \\
\hline Flange & 608 & 2.32 \\
\hline Shear pin & 171 & 1.20 \\
\hline Assembly & 640 & 2.21 \\
\hline
\end{tabular}

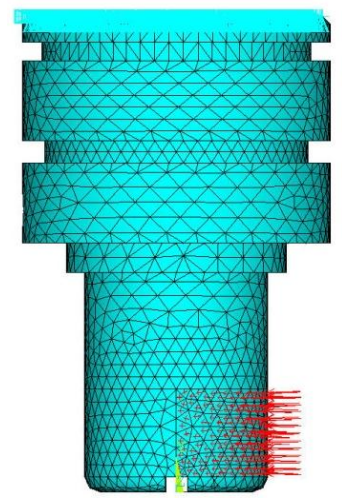

Figure-8 FE model of piston
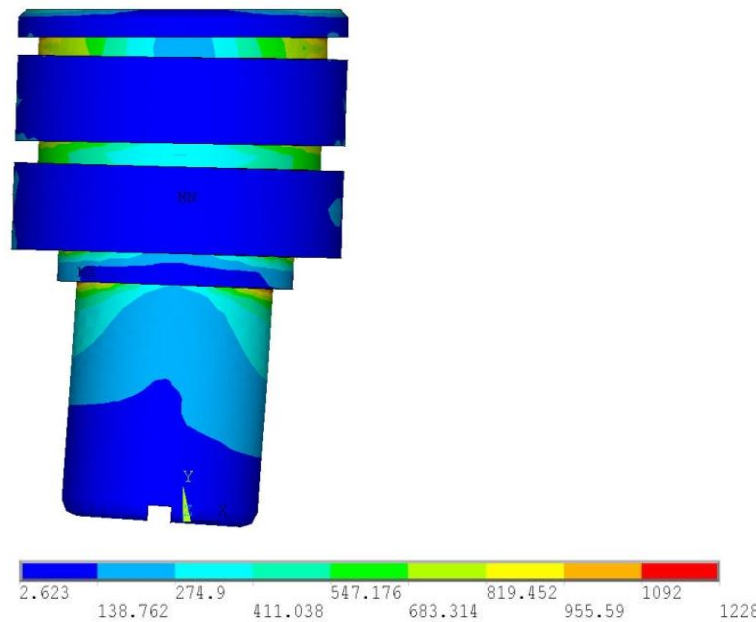

Figure-9 Von-mises stress plot of piston

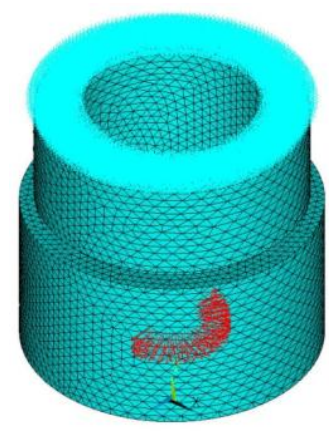

Figure-10 FE model of pyrobody
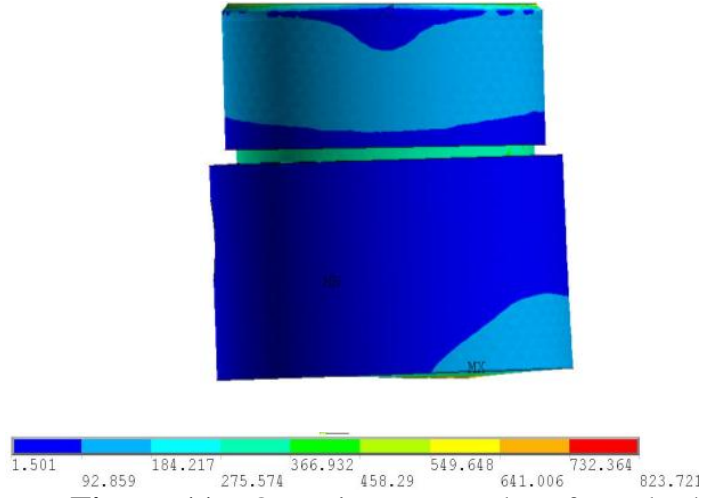

Figure-11 VON-mises stress plot of pyrobody

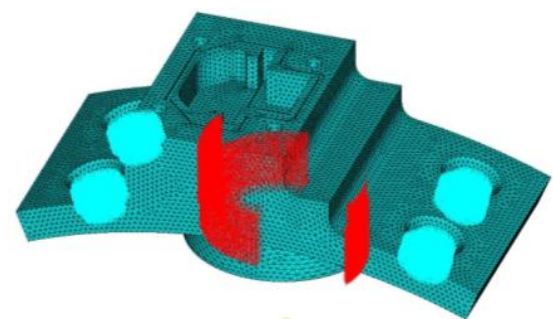

Figure-12 FE model of flange

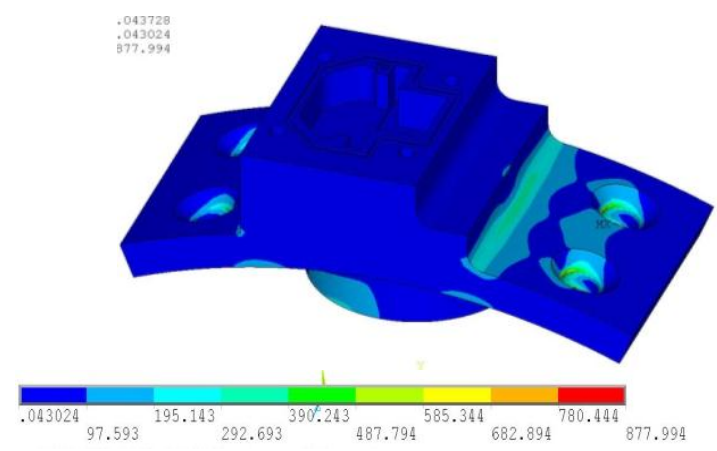

Figure-13 VON-mises stress plot of flange

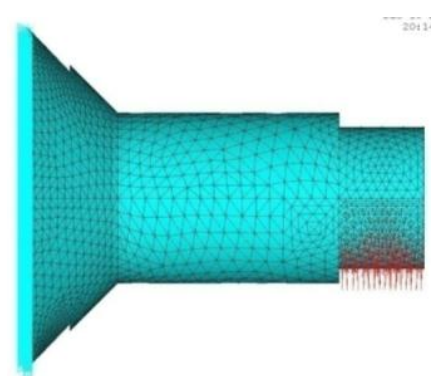

Figure-14 FE model of shear pin
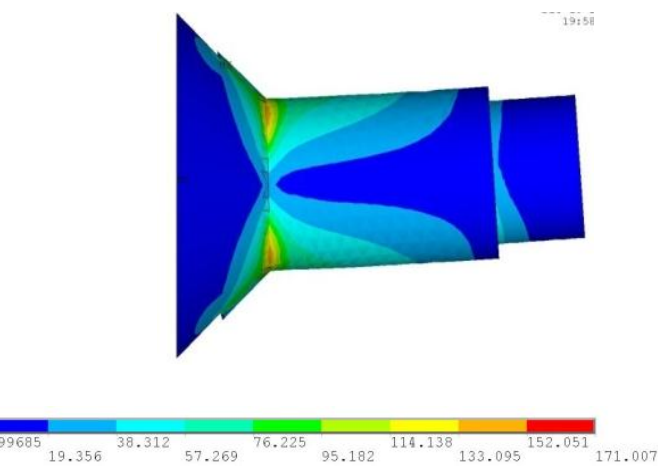

Figure-15 von-mises stress plot of shear pin 


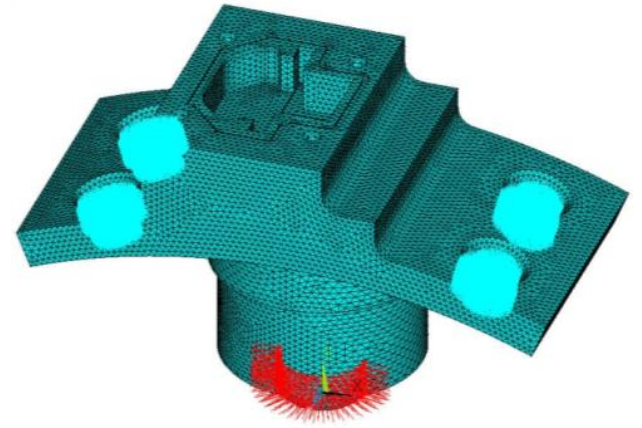

Figure-16 FE model of TLRM assembly
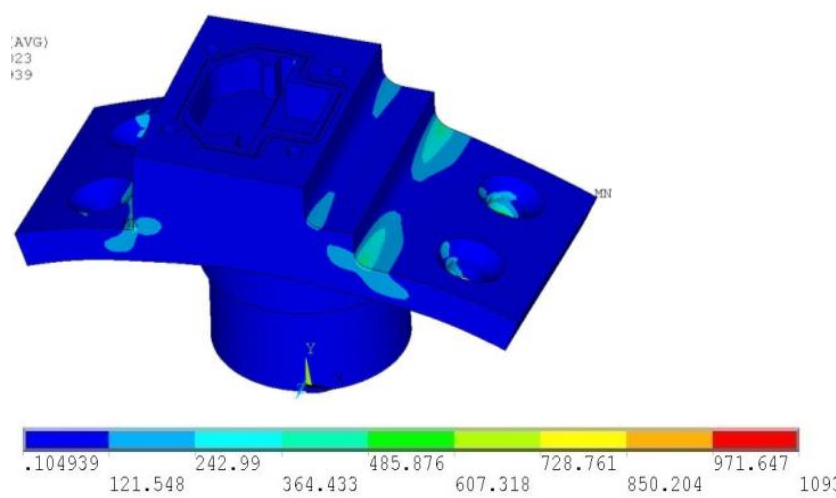

Figure-17 von-mises stress plot of tlrm assembly

\section{Conclusion}

The paper attempted to cover the conceptual design to practical design of a transportation lock and release mechanism. Even though, beam analysis approach is available, an attempt has been made to describe how it can be used to estimate the basic dimensions of the individual components for this kind of assembly and how these arrived basic dimensions are used in generating the FE model by incorporating the finer details which will be reflected in the actual hardware assembly. A pyro based transportation lock and release mechanism has been designed using classical design approach first and then analysed the same with finer details using finite element analysis to capture the precious stress distribution and to identify the stress concentration zone. The FOS obtained from the FEA of the components are of the same order as the FOS used in classical design to estimate the basic dimensions. Slight variations in the values of FOS are due to incorporation of finer details in FEA whereas in classical design only basic dimensions are considered / obtained. Here, the mechanism proposed is simple, less number of parts, easy to fabricate, lesser weight, more force to weight ratio and more force will be generated within less time and smaller volume of space. The TLRM has been fabricated, ground tested and field tested successfully in flight trials.

\section{Abbreviations \\ $\mathrm{d}=$ diameter $(\mathrm{mm})$ \\ $\mathrm{h}=$ height $(\mathrm{mm})$ \\ $\mathrm{F}=$ force $(\mathrm{N})$}

$\mathrm{M}=$ Bending moment $(\mathrm{N}-\mathrm{mm})$

$\mathrm{Z}=$ section modulus $\left(\mathrm{mm}^{3}\right)$

$\mathrm{S}=$ step size $(\mathrm{mm})$

$\mathrm{p}=$ pitch of threads

$\mathrm{R}=$ Radius $(\mathrm{mm})$

$\mathrm{t}=$ thickness $(\mathrm{mm})$

$\mathrm{e}=$ engagement length $(\mathrm{mm})$

$\mathrm{u}=$ undercut $(\mathrm{mm})$

FOS=Factor of Safety

UTS=Ultimate Tensile Strength (MPa)

$\sigma=$ Directional stress $(\mathrm{MPa})$

$\mathrm{C}=$ Couple of force $(\mathrm{N})$

$\mathrm{Pr}=$ pressure $(\mathrm{MPa})$

$\mathrm{F}_{\mathrm{ul}}=$ resisting force

$\mathrm{r}=$ distances between tilting edge and fastener

$\mathrm{T}=$ Torque $(\mathrm{N}-\mathrm{mm})$

$\mathrm{C}=$ constant of proportionality

$\mathrm{k}=$ stiffness

$\tau=$ Shear stress

$\mathrm{A}=$ Area

\section{Acknowledgements}

The authors are thankful to Director, Defence R\&D Laboratory (DRDL), Director, Advanced Systems Laboratory (ASL) and Project Director of NAG and HELINA, DRDL of Hyderabad for permitting to take up and publish this work and also would like to thank Dr R A Srivardhan of DRDL and D Basker of ASL for their valuable suggestions.

\section{References}

Laurence J. Bement and Morry L. Schimmel, (1995), A manual for pyrotechnic design, development and qualification, NASA Technical Memorandum 110172.

M.K. Abdul Majeed, K. Natarajan and V.K. Krishnan Kutty, (1984), Separation and Staging Mechanisms for Indian SVL-3 Launch Vehicle, Special Report from Vikram Sarabhai Space Centre, Indian Space Research Organization, Trivandrum, India, , Pp. 277-299

Ganesh V. Jadhav and Prof. S. B. Wadkar, (2012), Analysis of Ball Lock Separation Mechanism, IOSR Journal of Engineering (IOSRJEN), Volume 2, Issue 11, Pp. 39-45 S. Somanath, V. K. Krishnan Kutty and E. J. Francis, (2001), Dynamics Simulation of Pyro Actuated Ball Lock Separation System for Micro-Satellites to Evaluate Release Shock, 9th European Space Mechanisms and Tribology Symposium, ESA SP-480.

Cooper WP. (1996), Explosives Engineering, New York Wiley VCH publishers

Brauer K. V (1974), Handbook of pyrotechnics, Chemical publishing company, New York

Keith A Gauthier et al (1994), "Formulation Prediction and sensitivity analysis of a pyro technically actuated pin puller model" Journal of propulsion and power, Vol. 10, No4.

Timoshenko (1990), Strength Of Materials, PWS Publishing company, Boston MA

Timothy H Wentzell P.E. (2004), Machine Design, Thomson Delmar Learning, NY

Robert L. Norton (2000), Machine Design, Pearson Education Inc., Singapore. 